\title{
Millivolt per Second
}

National Cancer Institute

\section{Source}

National Cancer Institute. Millivolt per Second. NCI Thesaurus. Code C122216.

A SI derived rate unit equal to one millivolt per unit of time equal to one second. 